\title{
Progresso da mancha bacteriana do tomateiro em diferentes regimes de pulverização
}

\author{
Evaluation to tomato bacterial spot in different spray regimes
}

\section{Leandro Luiz Marcuzzo ${ }^{1 *}$, José Mauricio Cunha Fernandes² e Walter Ferreira Becker ${ }^{3}$}

Recebido em 20/05/2015 / Aceito em 29/10/2015

\section{RESUMO}

A mancha bacteriana do tomateiro é controlada por meio de pulverizações foliares com agrotóxicos seguindo um calendário fixo, sem considerar o progresso da doença. O regime de pulverização baseado em um modelo matemático pode predizer seu progresso e com isso possibilitar a redução do número de pulverizações e maximizar o controle da doença. Regimes de pulverização foram estabelecidos de acordo com a severidade estimada de 0,$05 ; 0,15$ e 0,25 por um modelo de previsão e comparados ao controle padrão (intervalo de pulverizações de 5 e 7 dias). Com o objetivo de avaliar o progresso da mancha bacteriana sob os diferentes regimes de pulverização foi aplicada a técnica de modelagem estatística conhecida por modelos mistos. Estes modelos não incluem apenas os efeitos fixos, mas também os efeitos aleatórios para cada um dos indivíduos da população em estudo. A severidade acumulada da mancha bacteriana em função do tempo, nos cinco regimes de pulverização foi calibrada com um modelo de Gompertz ajustado pelo modelo misto e o efeito aleatório ajustado à assíntota superior. Este parâmetro representa o potencial de severidade da doença para cada um dos tratamentos. Como resultado da calibração do modelo, o tratamento com a menor severidade foi a pulverização com severidade estimada em $0,05 \mathrm{com}$ 36 aplicações do fungicida com ação bactericida. No entanto, no tratamento com severidade estimada em 0,15 a severidade da doença foi reduzida em $26,28 \%$.

PALAVRAS-CHAVE: Solanum lycopersicon, epidemiologia, controle químico.

\section{ABSTRACT}

The control of tomato bacterial spot was carried out based on chemical spraying on a fixed schedule, without considering the progress of the disease. The spraying system based on a mathematical model can predict this progress and also reduce the number of sprays and maximize the disease control. Spraying regimes were established according to estimated severity of $0.05,0.15$, and 0.25 according to a previous published forecast model and compared with standard regimes with chemical applications at intervals of 5 and 7 days. In order to evaluate different spraying regimes on tomato bacterial leaf spot severity, the statistical modeling technique known as mixed models was applied. These models not only include fixed effects but also random effects to each one of the individuals of the population under study. Cumulative bacterial spot severity as a function of weeks after transplanting for five spraying regimes was calibrated to a Logistic model where the fit was obtained for the mixed model where a random effect was adjusted to the upper asymptote. This parameter represents the potential disease severity for each one of the treatments. As a result of model calibration, the treatment with the lowest disease severity was the one sprayed with estimated severity of 0.05 with 36 sprays of fungicide with bactericide action. However, the treatment with disease severity of 0.15 resulted in reduced disease severity of $26.28 \%$.

KEYWORDS: Solanum lycopersicon, epidemiology, chemistry control.

\footnotetext{
${ }^{1}$ Instituto Federal Catarinense, Rio do Sul, SC, Brasil.

${ }^{2}$ Empresa Brasileira de Pesquisa Agropecuária, Passo Fundo, RS, Brasil.

${ }^{3}$ Empresa de Pesquisa Agropecuária e Extensão Rural de Santa Catarina, Caçador, SC, Brasil.

*Autor para correspondência <marcuzzo@ifc-riodosul.edu.br>.
} 


\section{INTRODUÇÃO}

O tomate é uma das hortaliças de significativa expressão econômica no Brasil. Todavia, anualmente, doenças de diversas etiologias limitam sua produtividade. Entre elas, a mancha bacteriana do tomateiro (MBT) causada por um complexo de espécies pertencentes ao gênero Xanthomonas, a saber, $X$. euvesicatoria, $X$. vesicatoria, $X$. gardneri e $X$. perforans (JONES et al. 2004). Em levantamento realizado na região de Caçador (SC), foi constatada a prevalência de $X$. gardneri (COSTA et al. 2012).

Segundo BERGAMIM FILHO \& AMORIM (1996), os sistemas de previsão de doenças de plantas são representações simplificadas da realidade e preveem o início ou o desenvolvimento futuro de uma doença (KRAUSE \& MASSIE 1975, BARRETO et al. 2004, REIS 2004), além da previsão do momento adequado à pulverização com agrotóxicos, considerando que o patógeno se encontra em quantidades suficientes para iniciar uma epidemia e que o hospedeiro seja suscetível (MIZUBUTI 1999).

No estudo de epidemias, a dinâmica temporal das doenças de plantas é enfatizada, pois o progresso de doenças é frequentemente a manifestação mais facilmente visualizada (CAMPBELL \& MADDEN 1990). Na análise temporal de doenças, a análise da curva de progresso é a melhor representação de uma epidemia e a interpretação do formato dessas curvas e sua intensidade final são fundamentais para se efetuar o manejo de epidemias (BERGAMIN FILHO \& AMORIM 1996).

O uso de modelos matemáticos para explicar o progresso de doenças é uma ferramenta utilizada em diversas culturas. No tomateiro destaca-se o modelo linear múltiplo proposto por JARDINE \& STEPHENS (1987) para a previsão e controle de Pseudomonas syringae pv. tomato, expresso por $\mathrm{PB}=$ $0,98+0,72(\mathrm{R})-0,11(\mathrm{~T})+0,01(\mathrm{H})+0,51(\mathrm{P})$, em que PB: população bacteriana prevista; $\mathrm{T}$ : temperatura média no dia previsto; R: raiz quadrada (soma da chuva diária $+0,5$ para previsão de 6 dias); P: nível da população no tempo de amostragem; e H: arco seno da raiz quadrada para a média da umidade relativa para o dia previsto foram utilizado para verificação do progresso da doença e seu controle.

Em relação a Xanthomonas spp. na cultura do pimentão, CARMO et al. (1996a) avaliaram que o modelo logístico e de Gompertz proporcionaram o melhor índice de relação entre a intensidade da doença e seu desenvolvimento (CARMO et al. 1996b). O modelo de Gompertz também foi utilizado para a murcha bacteriana do tomateiro causada por Ralstonia solanacearum no agreste pernambucano (SILVEIRA et al. 1997).

Modelos não lineares, comumente usados para representar crescimento de epidemias, como o Logístico e o de Gompertz podem se comportar de forma diferente conforme a repetição, tratamento e unidade experimental. Mediante isso, os dados observados numa mesma unidade experimental ao longo do tempo são modelados mais adequadamente por modelos de efeitos mistos. Pois nesses casos, a análise de variância clássica leva à violação da independência entre as observações. Por outro lado, os modelos não lineares de efeitos mistos permitem explorar e modelar adequadamente a variabilidade de dados com erros aleatórios, coletados ao longo do tempo e, possivelmente com algum nível de correlação entre si no progresso de uma epidemia (DAVIDIAN \& GILTINAN 2003).

O objetivo deste estudo foi analisar o progresso da mancha bacteriana do tomateiro por meio da aplicação de modelos mistos e estimar qual regime de pulverização, baseado em um sistema de previsão, mais eficiente comparado ao sistema convencional de controle.

\section{MATERIAL E MÉTODOS}

\section{Detalhamento do Experimento}

O trabalho foi conduzido na Empresa de Pesquisa Agropecuária e Extensão e Rural de Santa Catarina S/A - Epagri, Estação Experimental de Caçador, no período de 13 de novembro de 2006 a 19 de março de 2007 totalizando 17 semanas após o transplantio das mudas. O delineamento experimental foi em blocos casualizados com cinco tratamentos e seis repetições, onde cada parcela foi constituída por 12 plantas, das quais dez plantas úteis.

Mudas de tomateiro cultivar Carmem com 25 dias de idade, produzidas em bandejas contendo substrato Plantmax ${ }^{\circledR}$ no sistema floating, foram transplantadas a campo e conduzidas no sistema de tutoramento vertical com uma planta e duas hastes no espaçamento de $1,5 \mathrm{~m}$ entre filas e $0,6 \mathrm{~m}$ entre plantas. A calagem, adubação e tratos culturais para a cultura foram efetuados conforme as recomendações da EPAGRI (1997).

A área do experimento era próxima a uma 
área de cultivo de tomateiro no ciclo anterior, provavelmente por isso a MBT ocorreu por infecção natural.

Durante a condução do experimento foi feito amostragem na área e a espécie foi identificada como $X$ gardneri.

Para o controle da MBT foram comparados os seguintes regimes de pulverização de Cuprozeb $^{\circledR}$ (mancozeb $(44 \%)+$ oxicloreto de cobre $(30 \%)$ na dose de $\left.200 \mathrm{~g} \mathrm{pc} \mathrm{hL}^{-1}: 1\right)$ sistema previsão com pulverização baseada no modelo descrito por MARCUZZO et al. (2009a): $\mathrm{SE}=0,0001538 *(((\mathrm{x}-$ $8)^{\left.2,4855647 *\left((32-\mathrm{x})^{0,7091962}\right)\right) *(0,64289 /(1+21,26122 *}$ $\left.\left.\exp \left(-0,12435^{*} \mathrm{y}\right)\right)\right)$, onde, SE: severidade estimada ( $\%$ severidade/100); $\mathrm{x}$ : temperatura média diária $\left({ }^{\circ} \mathrm{C}\right) ; \mathrm{y}$ : período de molhamento foliar (horas) atribuindo-se a $\mathrm{SE}=0,05 ; 2$ ) sistema de previsão com pulverização baseada no modelo anterior com $\mathrm{SE}=0,15 ; 3$ ) sistema previsão com pulverização baseada no modelo com $\mathrm{SE}=0,25 ; 4)$ sistema convencional com pulverização a cada 5 dias; 5) sistema convencional com pulverização a cada 7 dias. A pulverização no sistema de previsão foi realizada quando o somatório diário dos valores de SE $(0,05 ; 0,15$; e 0,25$)$ foi atingida, sendo então zerado o somatório e iniciada nova contagem dos valores de severidade diários.

A testemunha absoluta, sem pulverização, constou de 60 plantas cultivadas nas mesmas condições e afastadas a três metros dos demais tratamentos. A cada ocorrência de $25 \mathrm{~mm}$ de chuva, todos os tratamentos eram pulverizados, zerados e reiniciava-se a contagem do somatório dos valores de severidade.

As pulverizações nos sistemas de previsão iniciaram-se 50 dias após o transplantio, conforme estudo epidemiológico realizado previamente (MARCUZZO et al. 2009b). Os tratamentos de cinco e sete dias foram pulverizados desde o transplantio em condições normais de produção.

Para o controle de doenças fúngicas utilizouse clorothalonil (75\%) (200 g pc hL-1). A testemunha absoluta foi pulverizada apenas com clorothalonil. No controle de insetos-pragas utilizou-se o deltamethrine $(2,5 \%)\left(40 \mathrm{~mL} \mathrm{hL}^{-1}\right)$ e etofenproxi $(10 \%)(200 \mathrm{~mL} \mathrm{pc}$ $\left.\mathrm{hL}^{-1}\right)$ intercalados semanalmente.

\section{Avaliação da MBT}

A severidade da doença foi avaliada em termos da porcentagem de área total foliar infectada na planta, efetuada com auxílio da escala diagramática proposta por MELLO et al. (1997) a intervalos regulares de sete dias. A severidade da doença ao longo do ciclo foi integralizada e calculada a área abaixo da curva de progresso da doença (AACPD), através da fórmula: AACPD $=\sum[(y 1+y 2) / 2]^{*}(t 2-t 1)$, onde $y 1$ e $y 2$ refere-se a duas avaliações sucessivas da intensidade da doença realizadas nos tempos $t 1$ e $t 2$ (7 dias), respectivamente.

\section{Análise dos Dados}

Modelos não lineares utilizando o logístico e Gompertz foram usados para descrever o progresso da MBT no tempo em cada um dos tratamentos.

Após examinar as curvas de tendência em cada tratamento foi escolhido o modelo de Gompertz como adequado para representar a severidade acumulada da MBT em semanas após o transplante. Para os valores observados foi ajustado de acordo com as curvas de tendência um modelo de Gompertz definido por:

$$
\mathrm{y}_{\mathrm{ij}}=\mathrm{a} \times \exp ^{(-\mathrm{b} \times \mathrm{cxi})}
$$

onde, $\mathrm{y}_{\mathrm{ij}}$ representa a severidade (\%) na semana após o transplantio para o tratamento $\mathrm{j}, \mathrm{x}_{\mathrm{i}}$ é o número de semanas após o transplantio, a, o parâmetro a representa a assíntota superior, $b$, o ponto de inflexão e c é o parâmetro que indica a taxa de progresso. Os parâmetros estimados no modelo de efeitos fixos foram utilizados posteriormente para o ajuste do modelo misto não linear (DAVIDIAN \& GILTINAN 2003). Nesse caso, o modelo de Gompertz foi redefinido de acordo com a seguinte fórmula:

$$
\mathrm{y}_{\mathrm{ij}}=\left(\mathrm{a}+\mathrm{u}_{\mathrm{aj}}\right) \times \exp ^{(-\mathrm{b} \times \mathrm{cxi})}+\mathrm{e}_{\mathrm{ij}}
$$

onde $\mathrm{u}_{\mathrm{aj}}$ representa o efeito aleatório adicionado à assíntota para a representação individual de cada tratamento enquanto $\mathrm{e}_{\mathrm{ij}}$ representa o erro experimental. Nesta análise, a comparação de diferentes modelos com as combinações possíveis entre os efeitos fixos ( $a, b$ e c) e os aleatórios $\left(u_{a j}, u_{b j}\right.$ e $\left.u_{c j}\right)$ permitiu selecionar a adição de um único efeito aleatório para a assíntota do modelo não linear misto. O melhor ajuste foi obtido com o modelo representado pela equação 2. Os critérios utilizados para a seleção deste modelo foram o logaritmo da máxima verossimilhança (logLik), o critério de informação de Akaike (AIC), o critério de informação Bayesiano (BIC) e do desvio. Estes critérios são comumente usados para comparar o grau de ajuste entre os modelos, com o melhor 
modelo que apresentam os menores valores de todos esses critérios (SAKAMOTO et al. 1986).

Uma vez que os valores iniciais foram encontrados, o modelo misto não-linear foi ajustado com o nlmer que é um procedimento incluído no pacote lme4 (BATES et al. 2011) usando o método conhecido como aproximação de Laplace para o ajuste do modelo. Para a visualização, foi usado o pacote lattice (DEEPAYAN 2008). Ambos os pacotes fazem parte do software $\mathrm{R}$ de análise estatística versão 2.15.1 (R DEVELOPMENT CORE TEAM 2012).

A produtividade comercial $\left(\mathrm{t} \mathrm{ha}^{-1}\right)$ foi avaliada por frutos da classe extra AA ( $>150$ gramas) e extra A (100-150 gramas) foram avaliadas nos diferentes regimes de produção.

As médias da AACPD, severidade final e produtividade comercial $\left(t \mathrm{ha}^{-1}\right)$ entre os regimes de pulverização foram submetidas à análise de variância pelo teste de $\mathrm{F}$ a $5 \%$, e quando significativo foram comparadas estatisticamente pelo teste de Tukey ao nível de 5\%.

\section{RESULTADOS E DISCUSSÃO}

Para os sistemas de previsão propostos, podese constatar que o sistema $\mathrm{SE}=0,05$ proporcionou um aumento de $50 \%$ no número de pulverizações, quando comparado ao sistema de pulverização a cada cinco dias, e $111,76 \%$ quando as pulverizações foram realizadas de sete em sete dias (Tabela 1). Nas últimas quatro semanas, utilizou-se na $\mathrm{SE}=0,05$, em média, uma pulverização a cada dois dias, devido às condições de temperatura e molhamento foliar, o que resultou em um número de 36 pulverizações, porém a MBT foi reduzida nesse período (Figura 1).
No sistema $\mathrm{SE}=0,15$ houve uma redução de $29,16 \%$ no número de pulverizações, quando comparado ao sistema de aplicação a cada cinco dias, entretanto não houve diferença entre o $\mathrm{SE}=0,15$ e o sistema a cada sete dias. No $\mathrm{SE}=0,25$ o número de pulverizações semanais foi reduzido em $54,16 \%$, e $35,29 \%$ quando comparado a cada cinco e sete dias, respectivamente (Tabela 1 ).

Estudo realizado por JARDINE \& STEPHENS (1987) utilizando um sistema para a previsão de Pseudomonas syringae pv. tomato, constataram redução em até $25 \%$ no número de pulverizações para a pinta bacteriana do tomateiro. O uso de sistema de previsão na cultura do tomateiro na região de Caçador/SC também apresentou redução de aplicação de fungicidas em até $54,6 \%$ para a requeima causada por Phytophthora infestans (BECKER 2005) e redução de até $60,9 \%$ na quantidade de ingrediente ativo (BECKER et al. 2011).

$\mathrm{Na}$ área abaixo da curva de progresso da doença constatou-se redução de $25,71 \%$ no $\mathrm{SE}=0,15$ quando comparada à pulverização a cada 7 dias, sendo que ambas apresentaram o mesmo total de pulverizações. A comparação do sistema de previsão $\mathrm{SE}=0,15$ ou $\mathrm{SE}=0,25$ em relação à pulverização cada cinco dias, estes não diferiram entre si (Tabela 2).

De maneira geral, o progresso da doença ocorreu em níveis de severidade próximos até a sétima semana, com exceção do tratamento $\mathrm{SE}=0,05$, que resultou em redução logo a partir da quarta semana do início da ocorrência da doença (Figura 1).

$\mathrm{Na} \mathrm{SE}=0,15$ além da diferença estatística, ocorreu redução de 26,26\% (Tabela 2) na severidade final com o mesmo número (17) de pulverizações realizado semanalmente (Tabela 1 ).

Tabela 1 - Número de pulverizações semanais nos diferentes tratamentos dos sistemas de previsão e seu total em relação ao sistema convencional. EPAGRI, E.E. Caçador, 2006/2007.

Table 1 - Number of weekly sprayings in different forecast systems in relation to conventional system. EPAGRI, E.E. Caçador, 2006/2007.

\begin{tabular}{cccccccccccc}
\hline Tratamento & \multicolumn{10}{c}{ Semana } \\
\cline { 2 - 12 } & 1 & 2 & 3 & 4 & 5 & 6 & 7 & 8 & 9 & 10 & Total \\
\hline $\mathrm{SE}=0,05$ & 4 & 3 & 3 & 3 & 4 & 2 & 4 & 4 & 5 & 4 & 36 \\
$\mathrm{SE}=0,15$ & 1 & 2 & 0 & 1 & 2 & 1 & 2 & 3 & 3 & 2 & 17 \\
$\mathrm{SE}=0,25$ & 1 & 0 & 1 & 1 & 1 & 2 & 1 & 1 & 1 & 2 & 11 \\
\hline A cada 5 dias & & & & & & & & & & & 24 \\
A cada 7 dias & & & & & & & & & & &
\end{tabular}




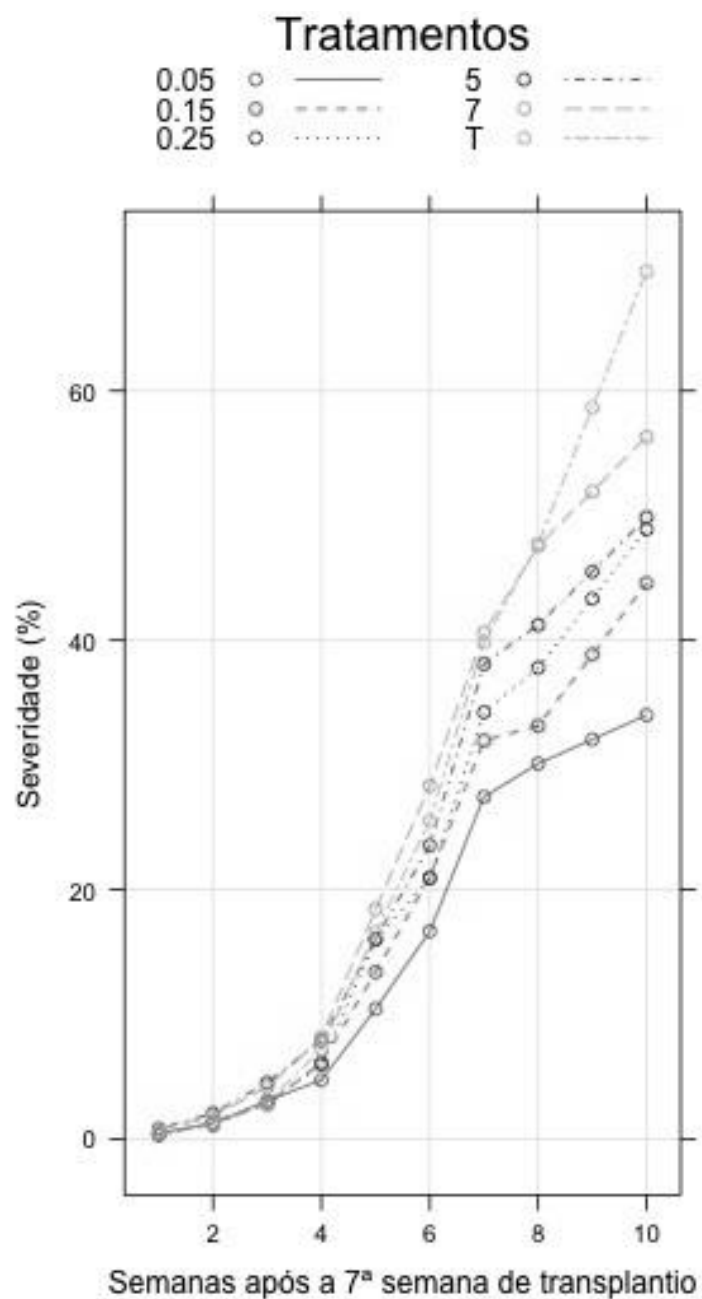

Figura 1 - Progresso da mancha bacteriana do tomateiro em diferentes regimes de pulverização. EPAGRI, E.E. Caçador, 2006/2007.

Figure 2 - Progress of tomato bacterial spot in different spray regimes. EPAGRI, E.E. Caçador, 2006/2007.

Tabela 2 - Área abaixo da curva de progresso da doença (AACPD), severidade final (\%) da mancha bacteriana e produtividade comercial $\left(\mathrm{t} \mathrm{ha}^{-1}\right)$ do tomateiro em diferentes regimes de pulverização. EPAGRI, E.E. Caçador, 2006/2007.

Table 2 - Area under the disease progress curve (AUDPC), final severity (\%) of tomato bacterial spot and commercial productivity $\left(\mathrm{t} \mathrm{ha}^{-1}\right)$ of tomato in different spray regimes. EPAGRI, E.E. Caçador, 2006/2007.

\begin{tabular}{cccc}
\hline Tratamento & AACPD & Severidade final $(\%)$ & Produtividade $\left(\mathrm{t} \mathrm{ha}^{-1}\right)$ \\
\hline $\mathrm{SE}=0,05$ & $936,81 \mathrm{c}$ & $34,00 \mathrm{c}$ & $77,85 \mathrm{~ns}$ \\
$\mathrm{SE}=0,15$ & $1114,93 \mathrm{bc}$ & $44,59 \mathrm{~b}$ & 75,74 \\
$\mathrm{SE}=0,25$ & $1205,71 \mathrm{~b}$ & $48,90 \mathrm{ab}$ & 76,92 \\
A cada 5 dias & $1337,18 \mathrm{ab}$ & $49,90 \mathrm{ab}$ & 77,63 \\
A cada 7 dias & $1500,80 \mathrm{a}$ & $56,31 \mathrm{a}$ & 79,07 \\
\hline $\mathrm{CV}(\%)$ & 12,22 & 11,64 & 12,52
\end{tabular}

Médias seguidas de mesma letra não diferem estatisticamente pelo teste de Tukey ao nível de 5\%. ns - não significativo pelo teste $\mathrm{F} 5 \%$. 
$\mathrm{Na} \mathrm{SE}=0,15$ ocorreu um progresso acentuado apenas nas últimas 3 semanas (Figura 1), decorrente do aumento do número de pulverizações em relação a $\mathrm{SE}=0,05$ (Tabela 1 ). No entanto isso não comprometeu a produtividade, já que nesse período os últimos frutos estavam em fase de maturação, porém constatou-se diferença estatística na severidade final entre esses dois tratamentos (Tabela 2). MARCUZZO et al. (2009b) verificaram que a evolução da MBT no tratamento testemunha é devido à agressividade em curto período de tempo, que começa a se manifestar a partir da maturação dos frutos do primeiro cacho, isto é, após a sétima semana após o transplantio do tomateiro na região de Caçador/SC, para a cultivar utilizada.

O momento correto da pulverização apresenta um manejo efetivo da doença com o mesmo número de pulverizações $(\mathrm{SE}=0,15)$ ou até menor $(\mathrm{SE}=0,25)$ ao realizado empiricamente pelo método de calendário fixo, que normalmente o produtor utiliza.

Ao se comparar o intervalo das médias nas diferenças da assíntota (asym) (Figura 2) sobre o efeito dos regimes de pulverização, verificou-se que $\mathrm{SE}=0,15$ encontra-se próximo do limiar intermediário a $\mathrm{SE}=0,05$ e $\mathrm{SE}=0,25$. No entanto, $\mathrm{SE}=0,25$ encontrase sobrepondo a pulverização a cada 5 dias, portanto não diferindo estatisticamente deste tratamento. Verifica-se também que a pulverização a cada 7 dias está muito próxima da testemunha, pressupondo que pulverizar ou não fez pouca diferença na redução da severidade da doença alcançada em relação ao tratamento testemunha.

No presente trabalho, constatou-se que no sistema de previsão $\mathrm{SE}=0,15$ houve uma redução na severidade da doença e no número de pulverização sem comprometer a produtividade (Tabela 2). Esse valor no sistema de previsão é um subsídio na tomada de decisão para o manejo da MBT. O uso do modelo de previsão tem por objetivo verificar se o comportamento do sistema real é coerente com o modelo construído (KRANZ \& HAU 1980, BERGAMIM FILHO \& AMORIN 1996). TENG (1985) afirma que o rigor da avaliação de um sistema de previsão não deve ser exagerado, uma vez que o sistema é uma aproximação da realidade e durante o processo de avaliação, se necessário, pode se ter um espaço entre o que é estimado e o real para aprimoramento contínuo do sistema (FERNANDES \& MAFFIA 1994).

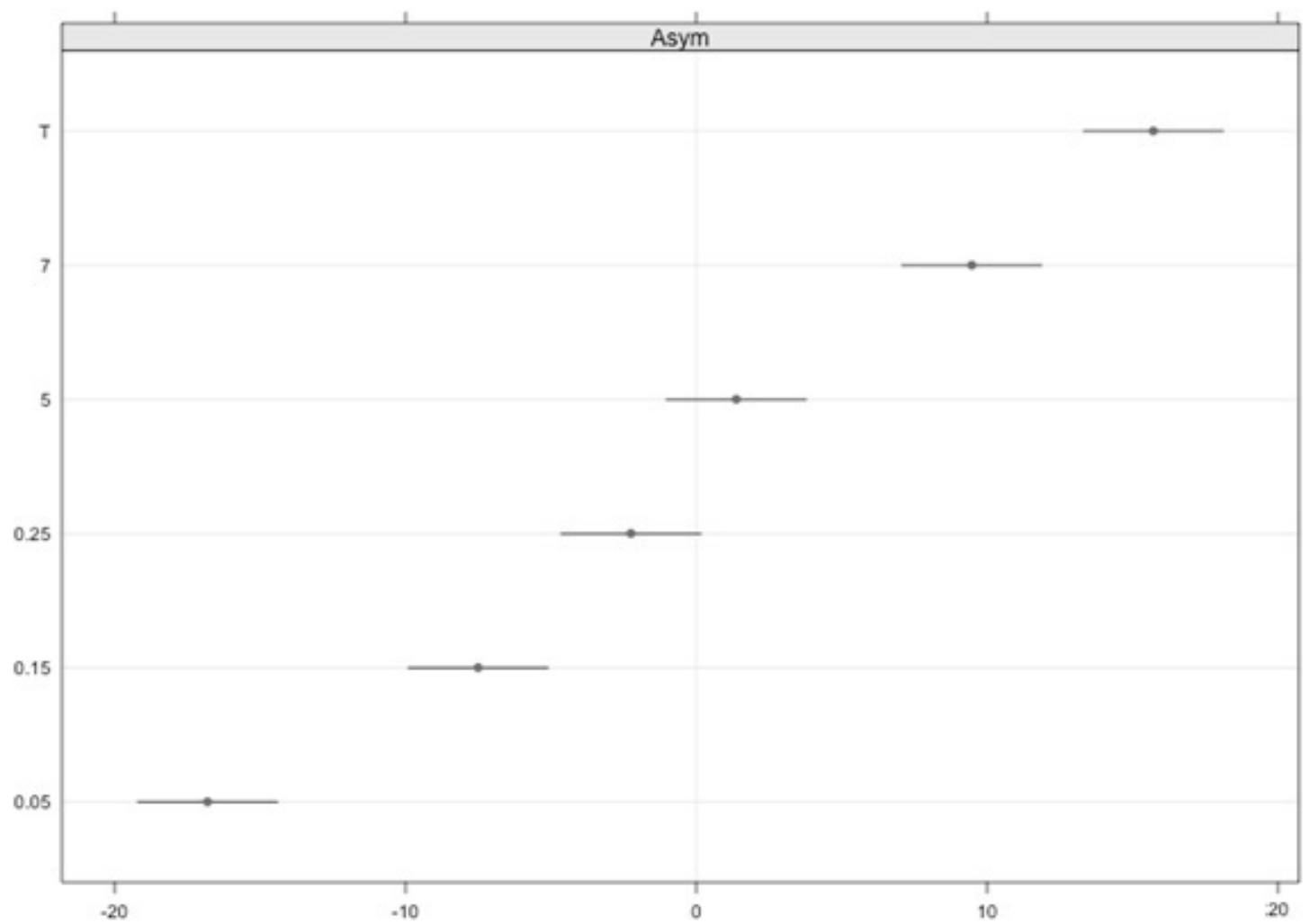

Figura 2 - Diferenças na assíntota (asym) dos dados de severidade da mancha bacteriana do tomateiro em diferentes regimes de pulverização. EPAGRI, E.E. Caçador, 2006/2007.

Figure 2 - Differences in asymptote (asym) of data severity of tomato bacterial spot in different spray regimes. EPAGRI, E.E. Caçador, 2006/2007. 


\section{CONCLUSÃO}

O uso da modelagem mista permitiu comparar o progresso temporal de epidemia da mancha bacteriana do tomateiro em função dos regimes de pulverização e constatou-se que é possível uma economia no número de pulverizações e redução na severidade da doença através da utilização do $\mathrm{SE}=0,15$ comparado com o empregado no sistema convencional (5 a 7 dias), servindo como uma ferramenta auxiliar no manejo integrado da doença.

\section{REFERÊNCIAS}

BARRETO M et al. 2004. Sistemas de previsão e estação de aviso. In: VALE FXR et al. Epidemiologia aplicada ao manejo de doenças de plantas. Belo Horizonte: Perffil. p.243-266.

BATES D et al. 2011. lme4: Linear mixed-effects models using S4 classes. R package version ISBN 0.999375-42. Disponível em: http://www.R-project.org. Acesso em: 15 dez. 2013.

BECKER WF 2005. Validação de dois sistemas de previsão para o controle da requeima do tomateiro na região de Caçador, SC. Agrop. Catar. 18: 63-68.

BECKER WF et al. 2011. Viability of a prediction system for tomato late blight in the integrated production of tomato in Caçador, Brazil. Hort. Bras. 29: 520-525.

BERGAMIM FILHO A \& AMORIM L. 1996. Doenças de plantas tropicais: epidemiologia e controle econômico. São Paulo: Ceres. 299p.

CAMPBELL CL \& MADDEN LV. 1990. Introduction to plant disease epidemiology. New York: Wiley Interscience. 532p.

CARMO MGF et al. 1996a. Progresso da pústula bacteriana do pimentão causada por Xanthomonas campestris pv. vesicatoria em condições de viveiro. Fitopatol. Bras. 21: 62-70.

CARMO MGF et al. 1996b. Disseminação da pústula bacteriana causada por Xanthomonas campestris pv. vesicatoria em condições de viveiro. Fitopatol. Bras. 21: 85-93.

COSTA JR et al. 2012. Ocorrência e caracterização do complexo de espécies causadoras da mancha bacteriana do tomateiro no Alto Vale do Rio do Peixe, SC. Trop. Plant Pathol. 37: 149-154.

DAVIDIAN M \& GILTINAN DM. 2003. Nonlinear Models for Repeated Measurement Data: An Overview and Update, Jabes. p.387-419.

DEEPAYAN S. 2008. Lattice: Multivariate Data Visualization with R. New York: Springer. Disponível em: http://www.R-project.org. Acesso em: 15 dez. 2013.

EPAGRI. 1997. Normas técnicas para o tomateiro tutorado na região do Alto Vale do Rio do Peixe. EPAGRI:
Florianópolis. $60 \mathrm{p}$.

FERNANDES JMC \& MAFFIA LA. 1994. Simulação de epidemias. Rev. Anu. Patol. Plantas 2: 293-334.

JARDINE DJ \& STEPHENS CTA. 1987. Predictive system for timing Chemical applications to control Pseudomonas syringae pv. tomato, causal agent of bacterial speck. Phytopathol. 77: 823-827.

JONES AL et al. 2004. Reclassification of the Xanthomonads associated with bacterial spot disease of tomato pepper. Syst. Appl. Microbiol. 27: 755-762.

KRANZ J \& HAU B. 1980. Systems analysis in epidemiology. Ann. Rev. Phytopathol. 18: 67-83.

KRAUSE RA \& MASSIE LB. 1975. Predictive systems: modern approaches to disease control. Ann. Rev. Phytopathol. 13: 31-47.

MARCUZZO LL et al. 2009a. Influência da temperatura e da duração do molhamento foliar na severidade da mancha bacteriana do tomateiro. Summa Phytopathol. 35: 229-230. MARCUZZO LL et al. 2009b. Alguns aspectos epidemiológicos da mancha bacteriana (Xanthomonas spp.) do tomateiro na região de Caçador/SC. Summa Phytopathol. 35: 132-135.

MELLO SC et al. 1997. Escala diagramática para avaliação da mancha-bacteriana do tomateiro. Fitopatol. Bras. 22: 447-448.

MIZUBUTI ESG. 1999. Sistema de previsão de doenças de plantas: Uma ferramenta útil? In: ZAMBOLIM L (Ed). $1^{\circ}$ Encontro de manejo integrado de doença e pragas. Viçosa: UFV. p.42-46.

R DEVELOPMENT CORE TEAM. 2012. R: A language and environment for statistical computing. R Foundation for Statistical Computing, Vienna, Austria. Disponível em: $<$ http://www.R-project.org $>$. Acesso em: 15 dez. 2013.

REIS EM. 2004. Previsão de doenças de plantas. Passo Fundo: UPF. 316p.

SAKAMOTO Y et al. 1986. Akaike Information Criterion Statistics. Dordrecht, Holland: Kluwer Academic Publishers. 256p.

SILVEIRA EB et al. 1997. Epidemiologia da murcha bacteriana do tomateiro estaqueado na região do agreste de Pernambuco. Fitopatol. Bras. 22:238.

TENG PSA. 1985. Comparison of simulation approaches to epidemic modeling. Ann. Rev. Phytopathol. 23:351-379. 